\title{
A Motivational Interviewing Intervention by Pharmacy Students to Improve Medication Adherence
}

\author{
Susan Abughosh, PhD; Xin Wang, MS; Omar Serna, PharmD, BCACP; \\ Tara Esse, PharmD, BCACP; Amanda Mann, PharmD; Santhi Masilamani, PharmD, CDE, MBA; \\ Marcia McDonnell Holstad, PhD, FNP-BC; Ekere James Essien, MD, DrPH; \\ and Marc Fleming, PhD, MPH
}

\begin{abstract}
BACKGROUND: Diabetes mellitus (DM) patients with comorbid hypertension (HTN) are at a higher risk of developing microvascular and macrovascular DM complications. Through guideline-driven recommendations, angiotensin-converting enzyme inhibitors (ACEls) and angiotensin II receptor blockers (ARBs) are highly recommended for these patients. Unfortunately, medication adherence to these products, though crucial to achieving therapeutic benefit, is frequently suboptimal. Motivational interviewing (MI) is a patient-centered collaborative communication style that is used to strengthen internal motivation for change that may prove effective in enhancing adherence.
\end{abstract}

OBJECTIVE: To examine the effect of an MI telephone intervention conducted by pharmacy students in improving adherence to ACEls/ARBs among Medicare Advantage Plan (MAP) patients with both DM and HTN.

METHODS: A prospective study was conducted among patients enrolled in a Texas MAP. Medical claims data were used to identify patients with DM and HTN, and pharmacy claims were observed to recognize those who filled either an ACEI or an ARB during June 2014. Patients with a 6-month proportion of days covered (PDC) $<0.80$ in the previous 6 months were determined nonadherent, and $75 \%$ of those were randomly selected to serve as potential subjects for the intervention, while $25 \%$ were randomly selected to serve as potential subjects for the control group. The intervention was a telephone call by a pharmacy student on rotation at the health plan, and 5 monthly follow-up calls. Before implementing calls, participating students attended a 3-day MI training course, where their proficiency for MI skills was evaluated. Refill data during the 6 -month postintervention were evaluated to examine the intervention effect measured on 3 outcomes: $\mathrm{PDC}$; $\mathrm{PDC} \geq 0.80$ versus $<0.80$; and discontinuation versus continuation. Multivariate linear and logistic regression models were constructed to adjust for any imbalances in baseline characteristics, including age, gender, number of other medications, regimen complexity, health low-income subsidy status, prescriber specialty, comorbidities, 6-month previous hospitalization, baseline 6-month PDC, and Centers for Medicare \& Medicaid Services risk score.

RESULTS: A total of 11 students participated in the intervention implementation. Patients receiving calls were randomly selected from those potential subjects for the intervention arm until a target of 250 was reached; 500 controls were randomly selected from the potential subjects for the control arm. The final cohort included in multivariate models consisted of 743 patients. Patients completing the initial call and at least 2 follow-ups were less likely to discontinue $(0 \mathrm{R}=0.29 ; 95 \% \mathrm{Cl}=0.15-0.54 ; P<0.001)$ and more likely to be adherent in the linear regression model $(\beta=0.0604$, $P<0.001)$ and the logistic regression model $(\mathrm{OR}=1.53 ; 95 \% \mathrm{Cl}=1.02-2.28$; $P=0.009)$. Other factors significantly associated with better adherence included higher baseline PDC and number of medications. Depression status was significantly associated with lower adherence.
CONCLUSIONS: Patients receiving 2 or more calls had significantly better adherence and less discontinuation during the 6 months following initial calls compared with those who did not receive calls. This finding indicates that an MI-based telephone intervention by pharmacy students may be a promising intervention to improve adherence. Future research should examine the sustainability of the intervention effect for longer time periods and its influence on associated clinical outcomes.

J Manag Care Spec Pharm. 2017;23(5):549-60

Copyright $\odot 2017$, Academy of Managed Care Pharmacy. All rights reserved.

\section{What is already known about this subject}

Motivational interviewing (MI) is a patient-centered communication style to strengthen motivation and commitment for change in a supportive, collaborative, empathetic manner and has been shown to promote behavioral change.

Telephone interventions by different health care professionals have been reported to improve patient care among diabetes mellitus (DM) patients.

Pharmacist interventions have been influential in promoting adherence among patients with DM and hypertension and among older adults, but they may have cost and time constraints.

\section{What this study adds}

Patients who received the initial MI telephone intervention and completed 2 or more follow-up calls had significantly fewer discontinuation rates and better adherence during the 6-month postintervention period.

This study demonstrated that an MI phone intervention had a promising effect on medication adherence.

The feasibility of training pharmacy students in MI and implementing an intervention by students was demonstrated in this study.

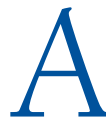
dherence to medication is a crucial step to achieving the full benefit of a prescribed treatment regimen and improving health outcomes. Approximately 20\%-50\% of patients with chronic illnesses are reported to be nonadherent to their medications, a situation that compromises treatment effectiveness. ${ }^{1-3}$ Among elderly patients, even higher nonadherence rates, ranging from $40 \%$ to $86 \%$, are reported, ${ }^{1,3,4}$ 
partially potentiated by an increased number of illnesses and a higher medication burden coupled with the cognitive decline of aging. ${ }^{2,5}$ The economic burden of nonadherence is considerable, costing $\$ 100$ billion annually in the United States. In addition, 33\%-69\% of medication-related hospital admissions result from poor adherence.,

Diabetes mellitus (DM) and hypertension (HTN) both remain major public health issues as well as a growing economic burden, with notable increases in elderly and obese individuals. ${ }^{7}$ In 2010 , approximately $6 \%$ of the U.S. population as a whole, and $27 \%$ of Americans aged 65 or older, had DM. $^{8,9}$ It is projected that 50 million Americans will be living with DM and 100 million with HTN by $2050 .{ }^{10}$ DM and HTN independently increase a patient's risk for cardiovascular disease (CVD), ${ }^{711-14}$ a major global cause of morbidity and mortality. ${ }^{15}$ Approximately $70 \%-80 \%$ of patients with DM also have HTN, ${ }^{7,16}$ and studies suggest an additive adverse effect on CVD outcomes. ${ }^{9}$ There is also a significant increase in the risk of developing microvascular and macrovascular complications of DM among patients with comorbid HTN, commonly referred to as the deadly duet. ${ }^{14}$

Angiotensin-converting enzyme inhibitors (ACEIs) and angiotensin II receptor blockers (ARBs) are highly recommended for patients with both DM and HTN, according to American Diabetes Association guidelines, ${ }^{8,14,15}$ with a benefit beyond blood pressure (BP) control alone. Clinical trials have demonstrated that ACEIs/ARBs decrease the risk of developing microvascular and macrovascular adverse events in this patient population..$^{8,17}$ ACEIs/ARBs have been shown to reduce allcause mortality, ${ }^{14,18-20}$ along with cardiac morbidity and mortality. ${ }^{14,18-21}$ Poor adherence to these medications continues to contribute to suboptimal BP control among DM patients, ${ }^{11,13,22-24}$ and fewer than 1 in 8 patients reach goal BP values as recommended by the guidelines. ${ }^{11,13,25}$ Reported nonadherence rates for DM populations within managed care organizations are $20 \%-50 \%, 23,26-30$ and only $50 \%$ of patients have been shown to take $80 \%$ or more of their DM or cardiovascular medication. ${ }^{26,30}$ Long-term persistence to antihypertensive therapy among DM patients remains low as well, 6,27 with reported adherence rates between $77 \%$ and $80 \%,{ }^{13,23,27}$ and a reported medication possession ratio to ACEI/ARB therapy of $0.77 .^{8}$ Interventions to improve adherence to ACEIs/ARBs among this high-risk population are greatly needed.

Motivational interviewing (MI) is a patient-centered communication style used to strengthen motivation and commitment for change ${ }^{31-33}$ in a supportive, collaborative, empathetic way. ${ }^{34}$ MI has demonstrated effectiveness in improving adherence $e^{35-37}$ and is recommended by the American Association of Diabetes Educators. ${ }^{38} \mathrm{MI}$ is a tactic employed by many health care professionals across the spectrum in an effort to improve medication adherence and overall health outcomes, and pharmacists are uniquely positioned to provide such services.
Studies have shown that pharmacists are beneficial in improving adherence among patients with $\mathrm{DM}^{39-43}$ and $\mathrm{HTN}^{44-48}$ and among older adults. ${ }^{40,49,50}$ To enhance adherence, pharmacists can counsel patients about their chronic disease and treatment, monitor medication use, and communicate with other health care professionals., ${ }^{540,51}$ Although pharmacy students have the knowledge and experience to provide similar services under pharmacist supervision, literature examining the potential influence of student interventions on adherence is lacking. The objective of this study was to examine the effect of a MI-based telephone intervention conducted by pharmacy students in improving adherence to ACEIs/ARBs among Medicare Advantage Plan (MAP) patients with DM and HTN.

\section{Methods}

\section{Study Design}

A prospective study was conducted using members enrolled in a Texas-based MAP. University of Houston (UH) College of Pharmacy fourth-year pharmacy students, who participated in 6-week advanced pharmacy practice experiential (APPE) rotations supervised by preceptors and pharmacy residents at the MAP, conducted/implemented the intervention.

\section{Data Description}

Several computerized de-identified data files, which included a membership file, a member summary file, an institutional claims file, a professional claims file, the MAP's care management system (CCMS), and a pharmacy claims file, were available for analysis. Membership and member summary files included demographic, Centers for Medicare \& Medicaid Services (CMS) risk scores, and yearly cost data for beneficiaries. Institutional claims included inpatient information claims with diagnostic information such as International Classification of Diseases, Ninth Revision, Clinical Modification (ICD-9-CM) codes and procedure information such as Current Procedural Terminology (CPT) codes. Professional claims contained outpatient encounter information as ICD-9-CM codes and CPT codes. Pharmacy files contained Part D pharmacy data provided by the MAP's pharmacy benefits manager and included patient and drug identifying information, fill dates, days supply, quantity dispensed, and dosing information for each prescription filled.

\section{Inclusion Criteria}

Subjects were included in the study if they had (a) enrollment in the MAP's drug plan between June 2014 and December 2015; (b) a diagnosis for DM and HTN identified through CCMS ICD-9-CM codes 250 and 401 between June 2014 and December 2014; and (c) a prescription filled for an ACEI or ARB medication during June 2014. Exclusion criteria included disenrollment from the plan, death before study end, a dementia diagnosis, and an ACEI/ARB use contraindication such as 
angioedema, hyperkalemia, and renal artery stenosis ${ }^{52,53}$ (identified by ICD-9-CM codes). This exclusion criteria was applied because patients with dementia have cognitive impairment that leads to noticeable decline in memory and thinking skills; therefore, adherence interventions to the general population cannot be effectively applied to this population. ${ }^{54}$ In addition, even though ACEIs and ARBs are the most frequently used classes of antihypertensive treatments, their use can also be associated with functional renal insufficiency and/or hyperkalemia. Therefore, ACEIs/ARBs should be discontinued or switched when the patients have these conditions.

Nonadherent patients were identified by evaluating 6-month refill data during June 2014 through December 2014. Patients were categorized as nonadherent if they had a proportion of days covered $(\mathrm{PDC})<0.80$ for their ACEI/ARB. If they switched to another ACEI or ARB, they were still considered to be covered. PDC is commonly used as a measure of adherence, which is defined as the number of follow-up days covered with medication divided by the total number of days in the follow-up period, ${ }^{55,56}$ and 0.80 , or $80 \%$, is generally considered adequate to achieve BP control. 6,23

\section{Protection of Human Subjects}

The protocol was approved by the UH institutional review board (IRB). Patients consented to the study before implementation of the intervention in accordance with all IRB requirements.

We randomly selected $75 \%$ of those patients meeting eligibility criteria identified as nonadherent to serve as potential subjects for the intervention group, and $25 \%$ of patients to serve as potential subjects for the control group using a random number generator program. More subjects were randomly selected as potential intervention subjects than controls to ensure that we could reach a minimum of 250 consenting patients by phone as determined by the sample size determination below. Baseline characteristics were equally distributed in these 2 groups.

\section{Sample Size Determination}

Using the $G^{*}$ Power 3.1 statistical software, ${ }^{57}$ and a primary endpoint of postintervention adherence rate, we determined a total sample of 459 subjects was adequate to provide $90 \%$ power to detect significance with a 0.15 effect size (relatively small effect size) for a two-tail analysis t-test at 0.05 a level. A total of 491 subjects were needed to provide $90 \%$ power to detect significance with a 0.17 effect size (relatively small effect size) for a chi-square analysis at a 0.05 a level. A total of 409 patients were needed for a two-tail logistic regression analysis at a $0.05 \alpha$ level and $0.10 \beta$ level (90\% power) and for a 1.5 odds ratio (OR), and approximately 230 patients were needed for a multiple linear regression analysis with an effect size of 0.10 . As a result, a total of at least 500 patients (250/group) were considered an adequate sample size given the various statistical tests and to have enough power to detect differences in case of a 5\%-7\% patient disenrollment from the plan (the usual rate in previous years is approximately $3 \%-5 \%$ per year).

\section{Training}

MI training for the pharmacy students was conducted over 3 days (June 5-7,2015) by an MI trainer who is a member of the Motivational Interviewing Network of Trainers. Students rotating at the MAP between June 2015 and April 2016 attended the training. In the first 2 days, training included lecture, discussion, demonstration, videos, and observed role playing of MI skills. On the last day, all students conducted 3 simulated telephone conversations with trained standardized patients (SPs). SPs portrayed problems with adherence, like forgetfulness or fear of side effects. These problems were identified in this patient population in our previous study. ${ }^{58}$

The practice calls were recorded for evaluation and feedback. The trainer evaluated each student's proficiency using a 7-point Likert-type scale ( 1 = poor/never to 7 = excellent/always) for MI skills and MI spirit, such as expressing empathy, using reflective listening, and eliciting change talk. General and individual feedback was given to students after evaluating the recorded calls. Students were then ready to begin implementing the intervention.

A total of 11 students at the MAP between June 2015 and April 2016 participated in the MI training. Mean scores of the trainer's evaluation of the student performances indicated average use of MI techniques, mostly ranging from 3 to 4 on a 7 -point scale, where 7 is maximum. Students received general and individual feedback from the trainer. Overall, the feasibility of the 3-day MI training session for pharmacy students was evaluated and students demonstrated beginning MI proficiency.

\section{Intervention}

The intervention consisted of 6 MI phone calls conducted by the specially trained pharmacy students on rotation at the MAP. All students were supervised by an MI-trained pharmacist or pharmacy resident. Call recipients were randomly selected from the list of identified nonadherent patients and randomly assigned to the intervention group until a target of 250 patients was reached. Follow-up monthly calls with nonadherent patients were conducted until 6 months after the initial call.

During the initial call, students first confirmed the diagnosis, medication name, and dosage with the patient and followed a general outline based on the Ask-Provide-Ask approach, ${ }^{32}$ a pharmacist adaptation for the Elicit-Provide-Elicit approach of MI. ${ }^{59-63}$ Using MI, the students helped patients identify barriers and helped guide the patient to develop a plan to deal with these barriers. After each call, students recorded the date and wrote a summary of the interaction with the patient, documenting the main barriers identified in the conversation and the plan made with the patient to achieve therapy goals. 
The summary information of the initial call was reviewed by students with a supervising pharmacist at the MAP before each monthly follow-up call. During the follow-up calls, students discussed the status of identified barriers, as well as plans and any additional problem solving. They provided encouragement and reinforced with the patient strategies discussed in the previous calls. Follow-up information was recorded and used for subsequent calls. For every patient who received the initial phone call, 2 patients were randomly selected from the list of patients identified as nonadherent and assigned to the control group $(\mathrm{n}=500)$.

\section{Outcome Measures}

An index date was defined as the initial intervention call date. For controls, the date when initial calls started was considered the index date. Refill data during the 6 months following the index date was evaluated to calculate adherence rates for both the intervention and control groups as PDC. PDC was calculated as the number of days during the 6 months on which the ACEI/ARB was available to the participant (total days supply) divided by the total number of days in that period, which was 180 days in this study. The PDC was truncated at 1.00 by removing any days of therapy extending beyond the analysis period, with a resulting ratio between 0 and 1 .

ACEIs or ARBs were considered together. In the event that a patient switched from an ACEI to an ARB or vice versa, the days supply for both the ACEI and ARB were summed. For a patient who had an ACEI or ARB added to his or her existing ARB or ACEI, the adherence measurement was considered for the initial drug.

Patients in both groups were also categorized as adherent and nonadherent during the 6-month follow-up period based on PDC $\geq 0.80$ to create a categorical outcome variable. PDC is used for measuring medication adherence in the Medicare Star Ratings program; $80 \%$ is the cutoff used to define medication adherence for the Medicare Star Ratings program to monitor and provide incentives to health plans with good scores on Medicare Star metrics. ${ }^{64}$ Discontinuation was also assessed, defined as no record of an ACEI/ARB during the 6 months following the initial intervention call.

\section{Other Measures and Variable Definition}

Baseline characteristics that could influence adherence and their comparability between the intervention and control groups were evaluated based on the index date. These characteristics included age; gender; number of other medications used/day; regimen complexity (defined as number of prescribed doses/day multiplied by number of medications, as used by Odegard et al. [2013, 2012]) $)^{42,43}$; income status (low-income subsidy [LIS] vs. no subsidy); prescriber specialty (primary care practitioner vs. specialist); comorbidities during the 6-month baseline period, including heart failure (HF), history of myocardial infarction, coronary artery disease, stroke, end-stage renal disease, and depression (categorized as having comorbidity vs. not having comorbidity); previous hospitalization during the 6 months before the index date versus no hospitalization; baseline adherence PDC during the 6 months before the index date; and the CMS risk score. The CMS risk score accounts for disease severity and medication burden and is calculated based on data from a pool of beneficiaries to estimate the average predicted costs for each of the component factors (e.g., gender, age, low-income status, individual disease groups). It consists of 189 disease classifications for use in risk adjusting of clinical outcomes in Medicare populations. ${ }^{65,66}$

\section{Statistical Analyses}

Baseline characteristics were compared between the 2 study groups (intervention vs. control) using Student t-tests for continuous variables and chi-square tests for categorical variables. PDCs for the invention and control groups during the 6 months following the intervention were compared using a t-test. Multiple linear regression with the 6-month PDC outcome was used to evaluate the intervention effect controlling for baseline characteristics not equally distributed between the 2 study groups. A logistic regression model with the categorical outcome based on a PDC $\geq 0.80$ cut-off was used to evaluate the intervention effect, adjusting for any imbalance in baseline characteristics. Logistic regression was also performed to assess the association between medication discontinuation with the outcome variable of discontinuation versus continuation, controlling for baseline characteristics. All statistical analyses were performed using SAS software version 9.3 (SAS Institute, Cary, NC) at a priori significance level of 0.05.

\section{Results}

\section{Data Analysis Before Intervention}

Data were obtained and analyzed between June 1 and June 21, 2015. A total of 50,197 patients were identified as having a diagnosis of DM and HTN. From this population, 36,332 were identified as having pharmacy claims for ACEIs or ARBs, with 31,865 having at least 180 days (6 months) of follow-up; 7,314 patients had a $\mathrm{PDC}<0.80$, with $5,851(80 \%)$ coded as English-speaking.

Approximately 5,851 patients meeting eligibility criteria were randomly selected in a 3:1 ratio to serve as potential subjects for the MI intervention group and the control group, resulting in 4,389 patients being placed in the intervention group and 1,462 patients in the control group. Results are presented in Figure 1. Patient characteristics such as gender, age, and baseline PDC value were equally distributed between the intervention and control groups, and no significant differences were detected $(P>0.05)$. 


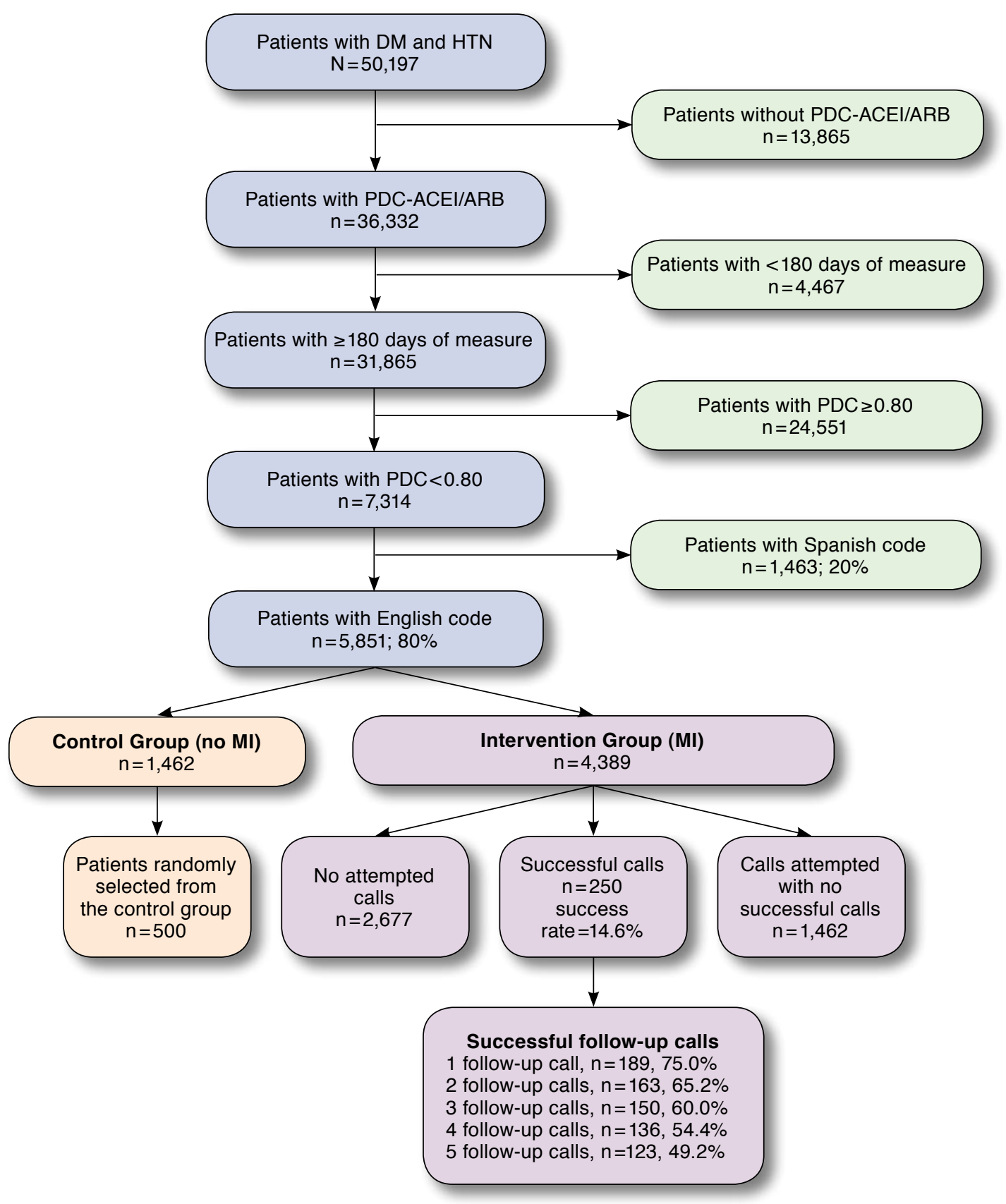

ACEI = angiotensin-converting enzyme inhibitor; $A R B=$ angiotensin II receptor blocker; $D M=$ diabetes mellitus; HTN = hypertension; PDC = proportion of days covered; MI = motivational interviewing.

\section{Intervention Calls}

Initial calls by MI-trained pharmacy students, under pharmacist supervision, were completed between June 22 and October 29, 2015. More than 1,700 calls were attempted to reach the target of 250 successful calls with consenting patients (success rate: $14.6 \%)$. On average, 18-20 successful calls were made per week by 2 students (averaging 9-10 per student). The average length of the initial call was approximately 12-13 minutes. Main 
TABLE 1 Descriptive Statistics of Baseline Sample Characteristics ( $N=743$ )

\begin{tabular}{|c|c|c|c|c|}
\hline & $\begin{array}{c}\text { Total } \\
\mathrm{N}=743 \\
\text { Frequency }(\%)\end{array}$ & $\begin{array}{c}\text { Intervention Group } \\
\mathrm{n}=248 \\
\mathrm{n}(\%)\end{array}$ & $\begin{array}{c}\text { Control Group } \\
n=495 \\
n(\%)\end{array}$ & $P$ Value \\
\hline Age, years $( \pm S D)$ & $69.79( \pm 10.23)$ & $72.35 \quad( \pm 10.01)$ & $68.51 \quad( \pm 10.11)$ & $<0.001^{\mathrm{a}}$ \\
\hline \multicolumn{5}{|l|}{ Gender } \\
\hline Female & $418 \quad(56.26)$ & $164 \quad(39.23)$ & $254 \quad(60.77)$ & $<0.001^{\mathrm{a}}$ \\
\hline Male & $325 \quad(43.74)$ & $84 \quad(25.85)$ & $241 \quad(74.15)$ & \\
\hline Specialty group & & & & 0.364 \\
\hline Specialist & $374 \quad(50.34)$ & $119 \quad(31.82)$ & $255 \quad(68.18)$ & \\
\hline Primary care & $369 \quad(49.66)$ & $129 \quad(34.96)$ & $240 \quad(65.04)$ & \\
\hline Regimen complexity & $23.86 \quad(21.04)$ & $26.28 \quad(20.81)$ & $22.65 \quad(21.07)$ & $0.026^{\mathrm{a}}$ \\
\hline Alc lab value before intervention & $6.52 \quad(3.52)$ & $6.59 \quad(3.43)$ & $6.47 \quad(3.61)$ & 0.784 \\
\hline Health plan & & & & 0.377 \\
\hline Low-income subsidy & $451 \quad(60.70)$ & $145 \quad(32.15)$ & $306 \quad(67.85)$ & \\
\hline Other & $(39.3)$ & $103 \quad(35.27)$ & $189 \quad(64.73)$ & \\
\hline Heart failure & $102 \quad(13.73)$ & $45 \quad(44.12)$ & $57 \quad(55.88)$ & $0.013^{\mathrm{a}}$ \\
\hline Depression & $97 \quad(13.06)$ & $28 \quad(28.87)$ & $69 \quad(71.13)$ & 0.312 \\
\hline Stroke & $33 \quad(4.44)$ & $33(100.00)$ & 0 & $<0.001^{\mathrm{a}}$ \\
\hline Myocardial infarction & $(1.88)$ & $3 \quad(21.43)$ & $11 \quad(78.57)$ & 0.338 \\
\hline Previous hospitalization & & & & 0.234 \\
\hline Yes & $251 \quad(33.78)$ & $91 \quad(36.25)$ & $160 \quad(63.75)$ & \\
\hline No & $492 \quad(66.22)$ & $157 \quad(31.91)$ & $335 \quad(68.09)$ & \\
\hline Number of medications at time of intervention $( \pm$ SD) & $10.93 \quad( \pm 6.75)$ & $12.25 \quad( \pm 7.11)$ & $10.27 \quad( \pm 6.47)$ & $<0.001^{\mathrm{a}}$ \\
\hline CMS risk score $( \pm \mathrm{SD})$ & $1.44 \quad( \pm 1.08)$ & $1.75 \quad( \pm 1.12)$ & $1.28 \quad( \pm 1.03)$ & $<0.001^{\mathrm{a}}$ \\
\hline PDC before intervention $( \pm$ SD) & $0.6144( \pm 0.1505)$ & $0.6348( \pm 0.1330)$ & $0.6042( \pm 0.1577)$ & $0.005^{\mathrm{a}}$ \\
\hline PDC after intervention $( \pm$ SD) & $0.5969( \pm 0.3705)$ & $0.6606( \pm 0.3376)$ & $0.5650( \pm 0.3822)$ & $<0.001^{\mathrm{a}}$ \\
\hline
\end{tabular}

reasons for unsuccessful calls included call back requested (5\%), declined (16\%), left voicemail (22\%), no answer (24\%), disenrolled from the MAP (5\%), and wrong/disconnected number (13.40\%). The follow-up calls were ongoing until April 2016, with an average length of 5-7 minutes.

Approximately half of the patients (123, 49.2\%) completed all 5 follow-up calls, while 136 (54.4\%) completed 4, 150 (60\%) completed 3, $163(65.2 \%)$ completed 2, and 189 (75\%) completed 1 follow-up call. The main barriers identified in calls included denial of nonadherence (32\%) and forgetfulness (23.6\%). Other reported barriers included high cost, modified (and often confusing) dosage instruction, high pill burden, side effects (perceived or experienced), transportation, and lack of disease state knowledge. The way each barrier was addressed is discussed in our previous study. ${ }^{58}$

\section{Multivariate Models Sample}

The cohort included in the multivariate regression models consisted of 743 patients, with 248 in the intervention group and 495 in the control group. Seven patients were excluded because of missing values. The baseline sample characteristics are presented in Table 1.

\section{Adherence}

In the linear regression model, which examined factors associated with better adherence, the MI phone call intervention for patients who completed 2 or more follow-up calls (3 MI phone calls or more in total) was significantly associated with better adherence $(\beta=0.0604, P<0.001)$. Higher medication adherence before intervention was also positively associated with better adherence after the intervention $(\beta=0.2234, P<0.001)$. The number of medications taken by patients at the time of intervention was positively associated with medication adherence after intervention $(\beta=0.0059, P=0.010)$. However, patients with HF $(\beta=-0.1259, P=0.002)$ and depression $(\beta=-0.0987$, $P=0.014)$ were less likely to adhere. These findings are summarized in Table 2.

In the logistic regression model, patients receiving 2 or more follow-up phone calls were more likely to become adherent after the intervention (OR: 1.53; 95\% confidence interval $[C I]=1.02-2.28, P=0.009)$. Patients with higher medication adherence before the intervention (prior PDC $\geq 0.50$ ) were more likely to become adherent after the intervention (OR: 3.10; 95\% CI $=1.98-4.86 ; P<0.001)$. Patients taking a higher number of medications at the time of the intervention were more likely 


\begin{tabular}{|c|c|c|}
\hline $\begin{aligned} \text { TABLE } 2 & \text { Result of Linear Re } \\
& \text { Examine Factors } \\
& \text { Adherence }(\mathrm{N}=74\end{aligned}$ & $\begin{array}{l}\text { gression M } \\
\text { ssociated V } \\
\text { 3) }\end{array}$ & $\begin{array}{l}\text { del to } \\
\text { th Better }\end{array}$ \\
\hline Variable & $\beta$ Coefficient & $P$ Value \\
\hline Intercept & 0.2567 & $0.017^{a}$ \\
\hline Baseline PDC & 0.2234 & $<0.001^{\mathrm{a}}$ \\
\hline Intervention & 0.0604 & $<0.001^{\mathrm{a}}$ \\
\hline Number of medications at time of intervention & 0.0059 & $0.010^{\mathrm{a}}$ \\
\hline CMS risk score & -0.0155 & 0.278 \\
\hline Regimen complexity & -0.00003075 & 0.325 \\
\hline Age & 0.0020 & 0.135 \\
\hline Gender & 0.0041 & 0.877 \\
\hline Heart failure & -0.1259 & $0.002^{\mathrm{a}}$ \\
\hline Depression & -0.0987 & $0.014^{a}$ \\
\hline Previous hospitalization & -0.0265 & 0.385 \\
\hline Health plan & 0.0031 & 0.908 \\
\hline Stroke & -0.0073 & 0.911 \\
\hline Myocardial infarction & 0.0550 & 0.569 \\
\hline Specialty group & -0.0338 & 0.196 \\
\hline
\end{tabular}

to be adherent (OR: 1.03; 95\% CI=1.002-1.060; $P=0.033$ ). However, patients with depression were less likely to be adherent (OR: $0.42 ; 95 \% \mathrm{CI}=0.24-0.70 ; P=0.001)$. The results of the logistic regression model are presented in Table 3.

Results of the logistic regression for medication discontinuation showed that patients receiving 2 or more followup phone calls were less likely to discontinue (OR: 0.29; $95 \% \mathrm{CI}=0.15-0.54 ; P<0.001)$ and patients with higher medication adherence before the intervention (prior $\mathrm{PDC} \geq 0.50$ ) were less likely to discontinue (OR: $0.34 ; 95 \% \mathrm{CI}=0.22-0.52$; $P<0.001)$. Additionally, patients with HF were more likely to discontinue (OR: 2.31;95\% CI=1.34-3.98; $P=0.002$ ). The results of the logistic regression model are presented in Table 4.

\section{Discussion}

The MI-based telephone intervention by pharmacy students may be a promising intervention to improve adherence to ACEIs/ARBs among nonadherent patients enrolled in a MAP with comorbid DM and HTN. Patients who received the initial call and completed 2 or more follow-up calls had significantly less discontinuation and better adherence rates measured as PDC, as well as PDC $>0.80$, during the 6-month postintervention start.

There are more than 32 million Medicare patients receiving prescription drug benefits through MAPs or Medicare Part D. ${ }^{67}$ Improving medication adherence among these patients can enhance CMS Star measures related to quality, which are linked to reimbursement, ${ }^{68-70}$ thus making adherence to ACEIs/ ARBs a priority for MAPs, given the health improvements and cost savings that can result.

\begin{tabular}{|c|c|c|}
\hline $\begin{array}{l}\text { Results of Logistic } \\
\text { Examine Factors } A \\
\text { Adherence }(\mathrm{N}=74\end{array}$ & $\begin{array}{l}\text { Regression Mo } \\
\text { ssociated with } \\
\text { 3) }\end{array}$ & $\begin{array}{l}\text { del to } \\
\text { Better }\end{array}$ \\
\hline Variable & OR $(95 \% \mathrm{CI})$ & $P$ Value \\
\hline Intervention & & $0.009^{\mathrm{a}}$ \\
\hline$\geq 2$ follow-up calls & $1.53 \quad(1.02-2.28)$ & \\
\hline$<2$ follow-up calls & $0.65 \quad(0.38-1.10)$ & \\
\hline No phone call & 1 & \\
\hline Prior PDC & & $<0.001^{a}$ \\
\hline$<0.50$ & 1 & \\
\hline $0.50-0.80$ & $3.10 \quad(1.98-4.86)$ & \\
\hline Age & $1.01 \quad(0.99-1.02)$ & 0.315 \\
\hline Gender & & 0.830 \\
\hline Male & $1.03 \quad(0.75-1.42)$ & \\
\hline Female & 1 & \\
\hline Specialty group & & 0.180 \\
\hline Specialist & $0.80 \quad(0.59-1.10)$ & \\
\hline Primary care & 1 & \\
\hline Previous hospitalization & & 0.112 \\
\hline No & 1 & \\
\hline Yes & $0.74 \quad(0.51-1.07)$ & \\
\hline Regimen complexity & $1.00(0.990-1.001)$ & 0.055 \\
\hline Number of medications at time of intervention & $1.03(1.002-1.060)$ & $0.033^{\mathrm{a}}$ \\
\hline CMS risk score & $0.99 \quad(0.83-1.18)$ & 0.960 \\
\hline Depression & $0.42 \quad(0.24-0.70)$ & $0.001^{a}$ \\
\hline Health plan & & 0.967 \\
\hline Low-income subsidy & 1 & \\
\hline Other & $0.99 \quad(0.71-1.38)$ & \\
\hline Heart failure & $0.62 \quad(0.37-1.04)$ & 0.073 \\
\hline Stroke & $1.18 \quad(0.53-2.62)$ & 0.682 \\
\hline Myocardial infarction & $1.55 \quad(0.48-4.99)$ & 0.461 \\
\hline $\begin{array}{l}\text { a Significance level } a<0.05 . \\
C I=\text { confidence interval; } C M S=\text { Centers for Me } \\
\text { OR=odds ratio; } P D C=\text { proportion of days cover }\end{array}$ & \& Medicaid Service & \\
\hline
\end{tabular}

Telephone-based interventions by different health care professionals have been reported to improve patient care among DM patients..$^{71-74}$ One study demonstrated the benefit of a telephone intervention by community pharmacists in improving adherence to antidiabetic medications and ACEIs. ${ }^{42,43}$ Pharmacists contacted patients who were 6 or more days late for refills, and in a brief amount of time, were able to successfully identify the patient's self-reported adherence barriers and provide assistance that improved overall adherence. ${ }^{42}$ Such interventions, however, cannot be widely implemented because of the high pharmacist cost and time constraints, as well as a pharmacy business model that is largely driven by the number of dispensed prescriptions. ${ }^{42}$

However, pharmacy students, under the direct supervision of pharmacists, can be effective in providing similar services at a lower cost coupled with an enriched educational experience. Several studies have demonstrated the benefit of pharmacy student participation in a variety of clinical settings. ${ }^{75-83}$ 


\begin{tabular}{|c|c|c|}
\hline $\begin{aligned} & \text { TABLE } 4 \text { Results of Logistic } \\
& \text { to Examine Factor } \\
& \text { Medication Discon }\end{aligned}$ & $\begin{array}{l}\text { Regression } \mathrm{Mo} \\
\text { Associated wi } \\
\text { inuation }(\mathrm{N}=7\end{array}$ & \\
\hline Variable & OR $(95 \% \mathrm{CI})$ & $P$ Value \\
\hline Intervention & & $<0.001^{\mathrm{a}}$ \\
\hline$<2$ follow-up calls & $1.42 \quad(0.81-2.47)$ & \\
\hline$\geq 2$ follow-up calls & $0.29 \quad(0.15-0.54)$ & \\
\hline No phone calls & 1 & \\
\hline Prior PDC & & $<0.001^{\mathrm{a}}$ \\
\hline$<0.50$ & 1 & \\
\hline $0.50-0.80$ & $0.34 \quad(0.22-0.52)$ & \\
\hline Age & $0.98 \quad(0.96-1.01)$ & 0.199 \\
\hline Gender & & 0.798 \\
\hline Male & $0.95 \quad(0.65-1.39)$ & \\
\hline Female & 1 & \\
\hline Specialty group & & 0.492 \\
\hline Specialist & $1.13 \quad(0.78-1.65)$ & \\
\hline Primary care & 1 & \\
\hline Previous hospitalization & & 0.570 \\
\hline No & 1 & \\
\hline Yes & $1.13 \quad(0.73-1.75)$ & \\
\hline Regimen complexity & $1.00(1.00-1.001)$ & 0.837 \\
\hline Number of medications at time of intervention & $0.96(0.93-1.001)$ & \\
\hline CMS risk score & $1.14 \quad(0.93-1.38)$ & 0.192 \\
\hline Depression & $1.41 \quad(0.82-2.42)$ & 0.208 \\
\hline Health plan & & 0.715 \\
\hline Low-income subsidy & 1 & \\
\hline Other & $0.93 \quad(0.62-1.37)$ & \\
\hline Heart failure & $2.31 \quad(1.34-3.98)$ & $0.002^{a}$ \\
\hline Stroke & $0.82 \quad(0.28-2.39)$ & 0.727 \\
\hline Myocardial infarction & $0.99 \quad(0.26-3.69)$ & 0.990 \\
\hline $\begin{array}{l}\text { a Significance level } \alpha<0.05 . \\
C I=\text { confidence interval; } C M \\
O R=\text { odds ratio; } P D C=\text { propo }\end{array}$ & E Medicaid Ser & \\
\hline
\end{tabular}

An economic benefit was demonstrated in a previous study in which student interventions of patient education, order clarification, dosing adjustments, and lab monitoring yielded an overall savings of $\$ 6,000-\$ 24,000$ at a psychiatric hospital. ${ }^{80}$ Pharmacy students conducting an interactive educational program on safe use of over-the-counter medications among older adults demonstrated positive intentions for behavior change among participants. ${ }^{81}$ One study examined the impact of a counseling program among HF patients led by pharmacy students and residents, and $89 \%$ of patients receiving the intervention reported better medication understanding. Many medication errors were also prevented, with a cost avoidance of $\$ 4,241 .{ }^{82} \mathrm{~A} 5$-minute consultation by a pharmacy student to improve knowledge about influenza and tetanus-diphtheriapertussis vaccines among 198 participants showed that a targeted consultation can increase vaccination rates and change public views. ${ }^{83}$ Benefits described in these studies, however, were based primarily on self-reporting by students; our study examined refill data in a real-world environment to capture the potential improvement.

Not all pharmacist interventions, however, have led to improvements in adherence. ${ }^{84,85}$ A Medicare Part D telephone medication therapy management program did not document any medication adherence benefit despite reported cost savings. ${ }^{86,87} \mathrm{~A}$ brief pharmacist telephone intervention in a similar population of nonadherent patients with DM and HTN resulted in significantly better PDCs during the 6 months following the intervention, but the overall PDC rates in both the intervention and control groups were still lower than the recommended $80 \%$.

Enhancing adherence to clinically meaningful values requires more than a brief pharmacist call. The style of communicating information to the patient can influence the intervention effectiveness. On the basis of our findings, incorporating MI strategies with follow-up calls to address barriers can be more influential in forming a sustainable behavioral change to improve adherence.

The intervention conducted in this study was based on the trans-theoretical model of behavioral change (TTM) in combination with MI techniques. The TTM describes behavior change as a progression through several stages, ${ }^{88-90}$ including the precontemplation, contemplation, preparation, action, and maintenance stages. ${ }^{88-90}$ TTM-based interventions have been beneficial among DM patients at different stages of readiness. ${ }^{91}$ MI strategies promote self-management behaviors such as medication adherence ${ }^{34}$ by eliciting and strengthening the patient's internal motivation to change..$^{92,93}$

MI is well suited for delivery by phone $e^{34,75}$ and can be delivered by trained students. ${ }^{94}$ MI promotes behavior change by contrasting the current behavior of nonadherence to desired goals of better outcomes and improved quality of life in a way that is supportive, collaborative, empathetic, and evocative. MI acknowledges autonomy; e.g., that the patient has every right to make no change, but uses a guided communication style that invites patients to consider their situation and find solutions to what they identify as problematic to facilitate a positive change while respecting patient autonomy. ${ }^{93}$ Counseling can be based on patient readiness and stage of behavioral change to maximize engagement. ${ }^{34}$

MI has been used to promote behavioral changes in alcohol abuse,,$^{95}$ smoking cessation, weight loss, drug addiction, ${ }^{96}$ selfcare for DM patients, ${ }^{93,97}$ and enhanced medication adherence with several chronic illnesses such as HTN, ${ }^{35}$ asthma, ${ }^{36}$ and HIV. $^{37,98}$ Offering MI training during student introductory practice experiences and APPEs can help incorporate MI practices into the delivery of pharmaceutical care across various settings, with graduating pharmacy students entering the work force as well trained in these behavioral change techniques.

It is worth noting that the effectiveness of MI interventions can also be influenced by several other factors, such as the 
length and number of intervention sessions, MI delivery mode, and provider's credentials. ${ }^{99}$ Menon et al. (2011) demonstrated that a single MI session may not be sufficient for a desired behavioral change. ${ }^{100}$ Our study evaluated the feasibility and effectiveness of using $3 \mathrm{MI}$ telephone intervention sessions to improve adherence.

Additionally, some comorbidities, including depression and $\mathrm{HF}$, were negatively associated with better adherence in this study. The social isolation feelings accompanying depression may reduce cognitive functioning, which can affect patient willingness and motivation to follow treatment protocol, resulting in lower adherence, as shown in previous literature., ${ }^{2,101}$

Nonadherence among patients with HF is common, ${ }^{102,103}$ possibly because of the increased regimen complexity and number of medications. ${ }^{104}$ Previous research has been inconsistent regarding the influence of pill burden on adherence. ${ }^{105-107}$ In this study, higher pill burden was associated with improved adherence, which could be because patients with more medications may be sicker and therefore more attentive to taking their medications. ${ }^{107}$ The baseline adherence before the intervention was also associated with better adherence, consistent with previous reports, ${ }^{108-110}$ even though the baseline adherence of the patients in this study was below $80 \%$.

\section{Limitations}

Several limitations to this study should be discussed. Prescription filling is not a guarantee that the patient actually took the medication, but refill rates are considered an acceptable measure of overall adherence. ${ }^{2,6}$ The study data did not capture prescriptions paid for by cash or verify the use of samples. While the initial random selection of the potential subjects for the intervention and control groups resulted in equal distribution of the major demographic variables between the groups, many patients randomly selected from the intervention group did not take the call or consent to the study, resulting in imbalances in some baseline characteristics. We later controlled for that in the multivariate analyses.

We also conducted analysis to test the difference in baseline sample characteristics among patients selected for the potential intervention group, across 3 groups: the group of patients with successful calls, the group of patients attempted to be reached but without successful calls, and the group of patients without attempted calls. There was no statistically significant difference in the baseline characteristics (age, gender, baseline PDC) across these different groups of patients. However, differences in other factors may exist between the patients who were willing to participate in the calls compared with those who were not willing or were not contacted. Such differences can only be addressed using a randomized design with an intentto-treat analysis.
Additionally, most patients in the intervention group completed 2 follow-up calls, but approximately $50 \%$ of consenting patients finished all 5 follow-up calls. Planning an intervention with 2 to 3 follow-up calls may be more feasible for the future and still effective in improving adherence. Information on some potential confounders, like side effects, health literacy, and perceived health, was noted.

We also were unable to account for hospitalizations during a follow-up period. The patients in this study were all Texas patients enrolled in the drug plan, and generalizability of findings is limited to similar subpopulations.

\section{Conclusions}

Patients receiving 2 or more calls had significantly better adherence and less discontinuation during the 6 months following initial calls compared with those who did not receive calls. This finding indicates that the MI-based telephone intervention by pharmacy students may be a promising intervention to improve adherence. Future research should examine the sustainability of the intervention effect for longer time periods and its influence on associated clinical outcomes.

Pharmacy students are a valuable, cost-saving resource that can be used to improve medication adherence. Participating in MI counseling opportunities can enhance skills they can carry into a variety of future practice settings.

\section{Authors}

SUSAN ABUGHOSH, PhD; XIN WANG, MS; EKERE JAMES ESSIEN, MD, DrPH; and MARC FLEMING, PhD, MPH, Department of Pharmaceutical Health Outcomes and Policy, University of Houston College of Pharmacy, Houston, Texas. OMAR SERNA, PharmD, BCACP; TARA ESSE, PharmD, BCACP; and AMANDA MANN, PharmD, Cigna-HealthSpring, Houston, Texas. SANTHI MASILAMANI, PharmD, CDE, MBA, and MARCIA MCDONNELL HOLSTAD, PhD, FNP-BC, Nell Hodgson Woodruff School of Nursing and Clinical and Social Science Integration, Emory Center for AIDS Research, Emory University, Atlanta, Georgia.

AUTHOR CORRESPONDENCE: Susan Abughosh, PhD, Department of Pharmaceutical Health Outcomes and Policy, University of Houston College of Pharmacy, 1441 Moursund St., Houston, TX, 77030.

Tel.: 832.842.8395; E-mail: smabugho@central.uh.edu.

\section{DISCLOSURES}

This project was supported by the Pharmaceutical Research and Manufacturers of America Foundation (PhRMA). The content is solely the responsibility of the authors and does not necessarily represent the official views of PhRMA. The funding agency was not involved in research design, analysis, or reporting results. Funding was obtained by Abughosh. Holstad provided a consultation regarding the MI guide and provided the MI training. 
Study concept and design were contributed by Abughosh and Fleming, along with Serna, Esse, and Holstad. Serna, Esse, Mann, Holstad, and Masilamani collected the data, and data interpretation was performed by Abughosh, Wong, and Esse. The manuscript was written by Abughosh, Wong, and Esse and revised by Masilamani and Holstad, along with the other authors.

\section{REFERENCES}

1. Butler RJ, Davis TK, Johnson WG, Gardner HH. Effects of nonadherence with prescription drugs among older adults. Am J Manag Care. 2011;17(2):153-60.

2. MacLaughlin EJ, Raehl CL, Treadway AK, Sterling TL, Zoller DP, Bond CA. Assessing medication adherence in the elderly: which tools to use in clinical practice? Drugs Aging. 2005;22(3):231-55.

3. Foreman KF, Stockl KM, Le LB, et al. Impact of a text messaging pilot program on patient medication adherence. Clin Ther. 2012;34(5):1084-91.

4. Kripalani S, Yao X, Haynes RB. Interventions to enhance medication adherence in chronic medical conditions: a systematic review. Arch Intern Med. 2007;167(6):540-50.

5. Murray MD, Morrow DG, Weiner M, et al. A conceptual framework to study medication adherence in older adults. Am J Geriatr Pharmacother. 2004:2(1):36-43.

6. Osterberg L, Blaschke T. Adherence to medication. N Engl J Med. 2005;353(5):487-97.

7. Deedwania PC. Blood pressure control in diabetes mellitus: is lower always better, and how low should it go? Circulation. 2011;123(24):2776-78.

8. Cooke CE, Fatodu H. Physician conformity and patient adherence to ACE inhibitors and ARBs in patients with diabetes, with and without renal disease and hypertension, in a Medicaid managed care organization. J Manag Care Pharm. 2006;12(8):649-55. Available at: http://www.jmcp.org/doi/ pdf/10.18553/jmcp.2006.12.8.649.

9. Jindal A, Whaley-Connell A, Sowers JR. Type 2 diabetes in older people; the importance of blood pressure control. Curr Cardiovasc Risk Rep. 2013;7(3):233-37.

10. Deshpande AD, Harris-Hayes M, Schootman M. Epidemiology of diabetes and diabetes-related complications. Physical Ther. 2008;88(11):1254-64.

11. McLean DL, Simpson SH, McAlister FA, Tsuyuki RT. Treatment and blood pressure control in 47,964 people with diabetes and hypertension: a systematic review of observational studies. Can J Cardiol. 2006;22(10):855-60

12. Sowers JR, Epstein M, Frohlich ED. Diabetes, hypertension, and cardiovascular disease: an update. Hypertension. 2001;37(4):1053-59.

13. Natarajan N, Putnam W, Van Aarsen K, Beverley Lawson K, Burge F. Adherence to antihypertensive medications among family practice patients with diabetes mellitus and hypertension. Can Fam Physician. 2013;59(2):e93-100.

14. Deedwania PC. Diabetes and hypertension, the deadly duet: importance, therapeutic strategy, and selection of drug therapy. Cardiol Clin. 2005;23(2):139-52

15. Lopez-Jaramillo P, Lopez-Lopez J, Lopez-Lopez C, Rodriguez-Alvarez MI The goal of blood pressure in the hypertensive patient with diabetes is defined: now the challenge is go from recommendations to practice. Diabetol Metab Syndr. 2014;6(1):31.

16. Putnam W, Lawson B, Buhariwalla F, et al. Hypertension and type 2 diabetes: what family physicians can do to improve control of blood pressurean observational study. BMC Fam Pract. 2011;12:86.

17. Adler AI, Stratton IM, Neil HA, et al. Association of systolic blood pressure with macrovascular and microvascular complications of type 2 diabetes (UKPDS 36): prospective observational study. BMJ. 2000;321(7258):412-19.

18. Effects of ramipril on cardiovascular and microvascular outcomes in people with diabetes mellitus: results of the HOPE study and MICROHOPE substudy. Heart Outcomes Prevention Evaluation Study Investigators. Lancet. 2000;355(9200):253-59.
19. Yusuf S, Sleight P, Pogue J, Bosch J, Davies R, Dagenais G. Effects of an angiotensin-converting-enzyme inhibitor, ramipril, on cardiovascular events in high-risk patients. The Heart Outcomes Prevention Evaluation Study Investigators. N Engl J Med. 2000;342(3):145-53.

20. Estacio RO, Jeffers BW, Hiatt WR, Biggerstaff SL, Gifford N, Schrier RW. The effect of nisoldipine as compared with enalapril on cardiovascular outcomes in patients with non-insulin-dependent diabetes and hypertension. N Engl J Med. 1998;338(10):645-52.

21. The ONTARGET Investigators. Telmisartan, ramipril, or both in patients at high risk for vascular events. N Engl J Med. 2008;358(15):1547-59.

22. Grant RW, Devita NG, Singer DE, Meigs JB. Polypharmacy and medication adherence in patients with type 2 diabetes. Diabetes Care 2003;26(5):1408-12.

23. Ho PM, Rumsfeld JS, Masoudi FA, et al. Effect of medication nonadherence on hospitalization and mortality among patients with diabetes mellitus. Arch Intern Med. 2006;166(17):1836-41.

24. Brown LC, Johnson JA, Majumdar SR, Tsuyuki RT, McAlister FA. Evidence of suboptimal management of cardiovascular risk in patients with type 2 diabetes mellitus and symptomatic atherosclerosis. CMAJ. 2004;171(10):1189-92.

25. McLean DL, McAlister FA, Johnson JA, et al. A randomized trial of the effect of community pharmacist and nurse care on improving blood pressure management in patients with diabetes mellitus: study of cardiovascular risk intervention by pharmacists-hypertension (SCRIP-HTN). Arch Intern Med. 2008;168(21):2355-61

26. Planas LG, Crosby KM, Mitchell KD, Farmer KC. Evaluation of a hypertension medication therapy management program in patients with diabetes. J Am Pharm Assoc (2003). 2009;49(2):164-70.

27. Schmittdiel JA, Uratsu CS, Karter AJ, et al. Why don't diabetes patients achieve recommended risk factor targets? Poor adherence versus lack of treatment intensification. J Gen Intern Med. 2008;23(5):588-94.

28. Lau DT, Nau DP. Oral antihyperglycemic medication nonadherence and subsequent hospitalization among individuals with type 2 diabetes. Diabetes Care. 2004;27(9):2149-53.

29. Grant R, Adams AS, Trinacty CM, et al. Relationship between patient medication adherence and subsequent clinical inertia in type 2 diabetes glycemic management. Diabetes Care. 2007;30(4):807-12.

30. Cramer JA, Benedict A, Muszbek N, Keskinaslan A, Khan ZM. The significance of compliance and persistence in the treatment of diabetes, hypertension and dyslipidaemia: a review. Int J Clin Pract. 2008;62(1):76-87.

31. Armstrong MJ, Mottershead TA, Ronksley PE, Sigal RJ, Campbell TS, Hemmelgarn BR. Motivational interviewing to improve weight loss in overweight and/or obese patients: a systematic review and meta-analysis of randomized controlled trials. Obes Rev. 2011;12(9):709-23.

32. Therapeutic Resource Center. Using motivational interviewing to create change. Online continuing education and webinars. Pharmacist's Letter. Volume 2012, Course No. 243, Self-Study Course \#120243. Available at: http://pharmacistsletter.therapeuticresearch.com/ce/cecourse.aspx?pc=12243\&AspxAutoDetectCookieSupport=1. Accessed March 18, 2017.

33. Miller WR, Rollnick S. Motivational Interviewing: Helping People Change. 3rd ed. New York: Guilford Press; 2012

34. Turner AP, Sloan AP, Kivlahan DR, Haselkorn JK. Telephone counseling and home telehealth monitoring to improve medication adherence: results of a pilot trial among individuals with multiple sclerosis. Rehabil Psychol. 2014:59(2):136-46.

35. Ogedegbe G, Chaplin W, Schoenthaler A, et al. A practice-based trial of motivational interviewing and adherence in hypertensive African Americans. Am J Hypertens. 2008;21(10):1137-43.

36. Halterman JS, Szilagyi PG, Fisher SG, et al. Randomized controlled trial to improve care for urban children with asthma: results of the school-based asthma therapy trial. Arch Pediatr Adolesc Med. 2011;165(3):262-68. 
37. Dilorio C, McCarty F, Resnicow K, et al. Using motivational interviewing to promote adherence to antiretroviral medications: a randomized controlled study. AIDS Care. 2008;20(3):273-83.

38. Haas L, Maryniuk M, Beck J, et al. National standards for diabetes self-management education and support. Diabetes Educ. 2012;38(5):619-29. Available at: https://www.diabeteseducator.org/docs/default-source/legacydocs/_resources/pdf/general/2012NationalStandards.pdf. Accessed March 18, 2017.

39. Moore JM, Shartle D, Faudskar L, Matlin OS, Brennan TA. Impact of a patient-centered pharmacy program and intervention in a high-risk group. J Manag Care Spec Pharm. 2013;19(3):228-36. Available at: http://www.jmcp. org/doi/pdf/10.18553/jmcp.2013.19.3.228.

40. Lindenmeyer A, Hearnshaw H, Vermeire E, Van Royen P, Wens J, Biot Y. Interventions to improve adherence to medication in people with type 2 diabetes mellitus: a review of the literature on the role of pharmacists. J Clin Pharm Ther. 2006;31(5):409-19.

41. Brennan TA, Dollear TJ, Hu M, et al. An integrated pharmacy-based program improved medication prescription and adherence rates in diabetes patients. Health Aff (Millwood). 2012;31(1):120-29.

42. Odegard PS, Carpinito G, Christensen DB. Medication adherence program: adherence challenges and interventions in type 2 diabetes. J Am Pharm Assoc (2003). 2013;53(3):267-72.

43. Odegard PS, Christensen DB. MAP study: RCT of a medication adherence program for patients with type 2 diabetes. J Am Pharm Assoc (2003). 2012;52(6):753-62

44. Morgado M, Rolo S, Castelo-Branco M. Pharmacist intervention program to enhance hypertension control: a randomised controlled trial. Int J Clin Pharm. 2011;33(1):132-40.

45. Fikri-Benbrahim N, Faus MJ, Martinez-Martinez F, Sabater-Hernández D Impact of a community pharmacists' hypertension-care service on medication adherence. The AFenPA study. Res Social Adm Pharm. 2013;9(6):797-805.

46. Lee JK, Grace KA, Taylor AJ. Effect of a pharmacy care program on medication adherence and persistence, blood pressure, and low-density lipoprotein cholesterol: a randomized controlled trial. JAMA. 2006;296(21):2563-71.

47. Lau R, Stewart K, McNamara KP, et al. Evaluation of a community pharmacy-based intervention for improving patient adherence to antihypertensives: a randomised controlled trial. BMC Health Serv Res. 2010;10:34.

48. Svarstad BL, Kotchen JM, Shireman TI, et al. Improving refill adherence and hypertension control in black patients: Wisconsin TEAM trial. J Am Pharm Assoc (2003). 2013;53(5):520-29.

49. Lowe CJ, Raynor DK, Purvis J, Farrin A, Hudson J. Effects of a medicine review and education programme for older people in general practice. $\mathrm{Br} \mathrm{J}$ Clin Pharmacol. 2000;50(2):172-75.

50. ASHP statement on the pharmacist's role in primary care. Am J Health Syst Pharm. 1999;56(16):1665-67.

51. Rybacki JJ. Improving cardiovascular health in postmenopausal women by addressing medication adherence issues. J Am Pharm Assoc (Wash). 2002;42(1):63-71; quiz 72-73.

52. Raebel MA. Hyperkalemia associated with use of angiotensin-converting enzyme inhibitors and angiotensin receptor blockers. Cardiovasc Ther. 2012;30(3):e156-66.

53. Schoolwerth AC, Sica DA, Ballermann BJ, Wilcox CS; Council on the Kidney in Cardiovascular Disease and the Council for High Blood Pressure Research of the American Heart Association. Renal considerations in angiotensin converting enzyme inhibitor therapy: a statement for healthcare professionals from the Council on the Kidney in Cardiovascular Disease and the Council for High Blood Pressure Research of the American Heart Association. Circulation. 2001;104(16):1985-91.

54. Arlt S, Lindner R, Rösler A, von Renteln-Kruse W. Adherence to medication in patients with dementia: predictors and strategies for improvement. Drugs Aging. 2008;25(12):1033-47.
55. Peterson AM, Nau DP, Cramer JA, Benner J, Gwadry-Sridhar F, Nichol M. A checklist for medication compliance and persistence studies using retrospective databases. Value Health. 2007;10(1):3-12.

56. Nau DP. Proportion of days covered (PDC) as a preferred method of measuring medication adherence. Pharmacy Quality Alliance. 2012. Available at: http://ep.yimg.com/ty/cdn/epill/pdcmpr.pdf. Accessed March 18, 2017.

57. Faul F, Erdfelder E, Buchner A, Lang A-G. Statistical power analyses using G*Power 3.1: Tests for correlation and regression analyses. Behav Res Methods. 2009;41(4):1149-60

58. Abughosh SM, Wang X, Serna O, et al. A pharmacist telephone intervention to identify adherence barriers and improve adherence among nonadherent patients with comorbid hypertension and diabetes in a Medicare Advantage Plan. J Manag Care Spec Pharm. 2016;22(1):63-73. Available at: http://www.jmcp.org/doi/pdf/10.18553/jmcp.2016.22.1.63.

59. Scales R, Miller J, Burden R. Why wrestle when you can dance? Optimizing outcomes with motivational interviewing. J Am Pharm Assoc (2003). 2003;43(5 Suppl 1):S46-47.

60. Gance-Cleveland B. Motivational interviewing: improving patient education. J Pediatr Health Care. 2007;21(2):81-88.

61. Borrelli B, Riekert KA, Weinstein A, Rathier L. Brief motivational interviewing as a clinical strategy to promote asthma medication adherence. J Allergy Clin Immunol. 2007;120(5):1023-30.

62. Possidente CJ, Bucci KK, McClain WJ. Motivational interviewing: a tool to improve medication adherence? Am J Health Syst Pharm. 2005;62(12):1311-14.

63. Butterworth SW. Influencing patient adherence to treatment guidelines. J Manag Care Pharm. 2008;14(6 Suppl B):21-24. Available at: http://www. jmcp.org/doi/pdf/10.18553/jmcp.2008.14.S6-B.21.

64. Schmittdiel JA, Nichols GA, Dyer W, Steiner JF, Karter AJ, Raebel MA. Health care system-level factors associated with performance on Medicare STAR adherence metrics in a large, integrated delivery system. Med Care. 2015;53(4):332-37.

65. Parikh NM, Morgan RO, Kunik ME, et al. Risk factors for dementia in patients over 65 with diabetes. Int J Geriatr Psychiatry. 2011;26(7):749-57.

66. Johnson ML, Parikh N, Kunik ME, et al. Antihypertensive drug use and the risk of dementia in patients with diabetes mellitus. Alzheimers Dement. 2012;8(5):437-44

67. Kaiser Family Foundation. The Medicare Part D Prescription Drug Benefit fact sheet. September 26, 2016. Available at: http://kff.org/medicare/ fact-sheet/the-medicare-prescription-drug-benefit-fact-sheet/. Accessed March 18, 2017.

68. Smart Retailing Rx. Insights for Better Pharmacy Health/Independent Pharmacy Blog. Star ratings explained. July 31, 2013. Available at: http:// smartretailingrx.com/regulatory-public-affairs/star-ratings-explained/. Accessed March 18, 2017.

69. MedicareHMO. Medicare Advantage and Prescription Drug Plan fact sheet. Available at: http://www.medicarehmo.com/factsheet. Accessed March 18, 2017

70. Scribd. Medicare Advantage Rankings fact sheet. 2015 star ratings. Available at: http://www.scribd.com/doc/242943563/Medicare-AdvantageRankings-Fact-Sheet\#scribd. Accessed March 18, 2017.

71. Piette JD, Weinberger M, Kraemer FB, McPhee SJ. Impact of automated calls with nurse follow-up on diabetes treatment outcomes in a Department of Veterans Affairs Health Care System: a randomized controlled trial. Diabetes Care. 2001;24(2):202-08.

72. Walker EA, Shmukler C, Ullman R, Blanco E, Scollan-Koliopoulus M, Cohen HW. Results of a successful telephonic intervention to improve diabetes control in urban adults: a randomized trial. Diabetes Care. 2011;34(1):2-7.

73. Wolever RQ, Dreusicke M, Fikkan J, et al. Integrative health coaching for patients with type 2 diabetes: a randomized clinical trial. Diabetes Educ. 2010;36(4):629-39. 
74. Walker EA, Schechter CB, Caban A, Basch CE. Telephone intervention to promote diabetic retinopathy screening among the urban poor. Am J Prev Med. 2008;34(3):185-91.

75. Abrons J, Vadala T, Miller S, Cerulli J. Encouraging safe medication disposal through student pharmacist intervention. J Am Pharm Assoc (2003). 2010;50(2):169-73

76. McCollum M, Nuffer W, Ellis SL, Turner CJ. Physician acceptance of pharmacotherapy recommendations made by pharmacy students in a rural pharmacy-based diabetes care and education clinic. Am J Pharm Educ. 2009;73(2):24.

77. Mueller BA, Abel SR. Impact of college of pharmacy-based educational services within the hospital. DICP. 1990;24(4):422-25.

78. Brockmiller H, Abel SR, Koh-Knox CP, Birk CW. Cost impact of Pharm.D. candidates' drug therapy recommendations. Am J Health Syst Pharm. 1999;56(9):882-84

79. Marino J, Cabellero J, Liosent L, Hinkes R. Differences in pharmacy interventions at a psychiatric hospital: comparison of staff pharmacists, pharmacy faculty, and student pharmacists. Hosp Pharm. 2010;45(4):314-19. 80. Campbell AR, Nelson LA, Elliott E, Hieber R, Sommi RW. Analysis of cost avoidance from pharmacy students' clinical interventions at a psychiatric hospital. Am J Pharm Educ. 2011;75(1):8.

81. Burgin LB, Gamboa AM, Tierney DM, Lee JK. Interactive approach by pharmacy students to educate older adults on the safe use of over-thecounter medications. Consult Pharm. 2013;28(3):168-75.

82. Szkiladz A, Carey K, Ackerbauer K, Heelon M, Friderici J, Kopcza K. Impact of pharmacy student and resident-led discharge counseling on heart failure patients. J Pharm Pract. 2013;26(6):574-79.

83. Chou TI, Lash DB, Malcolm B, et al. Effects of a student pharmacist consultation on patient knowledge and attitudes about vaccines. J Am Pharm Assoc (2003). 2014;54(2):130-37.

84. Grant RW, Devita NG, Singer DE, Meigs JB. Improving adherence and reducing medication discrepancies in patients with diabetes. Ann Pharmacother. 2003;37(7-8):962-69.

85. Odegard PS, Goo A, Hummel J, Williams KL, Gray SL. Caring for poorly controlled diabetes mellitus: a randomized pharmacist intervention. Ann Pharmacother. 2005;39(3):433-40.

86. Moczygemba LR, Barner JC, Lawson KA, et al. Impact of telephone medication therapy management on medication and health-related problems, medication adherence, and Medicare Part D drug costs: a 6-month follow up. Am J Geriatr Pharmacother. 2011;9(5):328-38.

87. Moczygemba LR, Barner JC, Gabrillo ER. Outcomes of a Medicare Part D telephone medication therapy management program. J Am Pharm Assoc (2003). 2012;52(6):e144-52.

88. Prochaska JO, DiClemente CC. Stages and processes of self-change of smoking: toward an integrative model of change. J Consult Clin Psychol. 1983;51(3):390-95.

89. Prochaska JO, DiClemente CC, Norcross JC. In search of how people change. Applications to addictive behaviors. Am Psychol. 1992;47(9):1102-14.

90. DiClemente CC, Prochaska JO, Fairhurst SK, Velicer WF, Velasquez MM, Rossi JS. The process of smoking cessation: an analysis of precontemplation, contemplation, and preparation stages of change. J Consult Clin Psychol. 1991;59(2):295-304

91. Jones H, Edwards L, Vallis TM, et al. Changes in diabetes self-care behaviors make a difference in glycemic control: the Diabetes Stages of Change (DiSC) study. Diabetes Care. 2003;26(3):732-37.

92. Miller WR, Rollnick S. Ten things that motivational interviewing is not. Behav Cogn Psychother. 2009;37(2):129-40.

93. Christie D, Channon S. The potential for motivational interviewing to improve outcomes in the management of diabetes and obesity in paediatric and adult populations: a clinical review. Diabetes Obes Metab. 2014;16(5):381-87.
94. Low KG, Giasson H, Connors S, Freeman D, Weiss R. Testing the effectiveness of motivational interviewing as a weight reduction strategy for obese cardiac patients: a pilot study. Int J Behav Med. 2013;20(1):77-81.

95. Brown RL, Saunders LA, Bobula JA, Mundt MP, Koch PE. Randomizedcontrolled trial of a telephone and mail intervention for alcohol use disorders: three-month drinking outcomes. Alcohol Clin Exp Res. 2007;31(8):1372-79.

96. Rubak S, Sandbaek A, Lauritzen T, Christensen B. Motivational interviewing: a systematic review and meta-analysis. Br J Gen Pract. 2005;55(513):305-12.

97. Hawkins SY. Improving glycemic control in older adults using a videophone motivational diabetes self-management intervention. Res Theory Nurs Pract. 2010;24(4):217-32.

98. Holstad MM, Dilorio C, Kelley ME, Resnicow K, Sharma S. Group motivational interviewing to promote adherence to antiretroviral medications and risk reduction behaviors in HIV infected women. AIDS Behav. 2011;15(5):885-96.

99. VanBuskirk KA, Wetherell JL. Motivational interviewing with primary care populations: a systematic review and meta-analysis. J Behav Med. 2014;37(4):768-80.

100. Menon U, Belue R, Wahab S, et al. A randomized trial comparing the effect of two phone-based interventions on colorectal cancer screening adherence. Ann Behav Med. 2011;42(3):294-303.

101. Cukor D, Rosenthal DS, Jindal RM, Brown CD, Kimmel PL. Depression is an important contributor to low medication adherence in hemodialyzed patients and transplant recipients. Kidney Int. 2009;75(11):1223-29.

102. van der Wal MH, Jaarsma T, van Veldhuisen DJ. Non-compliance in patients with heart failure; how can we manage it? Eur J Heart Fail. 2005;7(1):5-17.

103. van der Wal MH, Jaarsma T. Adherence in heart failure in the elderly: problem and possible solutions. Int J Cardiol. 2008;125(2):203-08.

104. Unni E, Farris KB. Determinants of different types of medication nonadherence in cholesterol lowering and asthma maintenance medications: a theoretical approach. Patient Educ Couns. 2011;83(3):382-90.

105. Abughosh SM, Kogut SJ, Andrade SE, Larrat P, Gurwitz JH. Persistence with lipid-lowering therapy: influence of the type of lipid-lowering agent and drug benefit plan option in elderly patients. J Manag Care Pharm. 2004;10(5):404-11. Available at: http://www.jmcp.org/doi/pdf/10.18553/ jmcp.2004.10.5.404.

106. Jackevicius CA, Mamdani M, Tu JV. Adherence with statin therapy in elderly patients with and without acute coronary syndromes. JAMA. 2002;288(4):462-67.

107. Shalansky SJ, Levy AR. Effect of number of medications on cardiovascular therapy adherence. Ann Pharmacother. 2002;36(10):1532-39.

108. Downer MK, Gea A, Stampfer M, et al. Predictors of short-and long-term adherence with a Mediterranean-type diet intervention: the PREDIMED randomized trial. Int J Behav Nutr Phys Act. 2016;13:67.

109. Chisholm-Burns MA, Spivey CA, Graff Zivin J, Lee JK, Sredzinski E, Tolley EA. Improving outcomes of renal transplant recipients with behavioral adherence contracts: a randomized controlled trial. Am J Transplant. 2013;13(9):2364-73.

110. Novick D, Haro JM, Suarez D, Perez V, Dittmann RW, Haddad PM. Predictors and clinical consequences of non-adherence with antipsychotic medication in the outpatient treatment of schizophrenia. Psychiatry Res. 2010;176(2-3):109-13. 